\title{
Bemerkungen zur vorliegenden Ausgabe.
}

Da inzwischen mein e Neuausgabe des koptischen Textes erschienen ist, sind die betreffenden Seiten am Rande mit schrägen Ziffern angegeben; die geraden Zahlen bedeuten die Seiten der Ausgabe von Schwartze-Petermann.

Die alte Kapiteleinteilung habe ich beibehalten, ebenso die Zerlegung der Psalmen und Hymnen in Verse. Die griechischen Wörter sind in Klammern beigesetzt, um dem Leser die griechische Grundlage der koptischen Übersetzung vor die Augen zu führen. Freilich habe ich den griechischen Index nicht wieder aufgenommen, da der Gelehrte ihn in meiner Textausgabe benutzen kann. Aus dieser Rücksicht auf das interessierte gebildete Laienpublikum sind die textkritischen Anmerkungen, wie ich in der Vorrede bereits bemerkt habe, fast ganz ausgemerzt. Die alt- und neutestamentlichen Parallelen sind dagegen angemerkt worden. Auch auf ein ausführliches Namen- und Sachregister glanbte ich nicht verzichten zu dürfen, um dem Erforscher des Gnostizismus und dem Religionshistoriker die Benutzung der Ausgabe als eines Nachschlagewerkes zu ermöglichen.

Was die Zeichen betrifft, so bedeutet:

$$
\begin{aligned}
&\langle\rangle=\text { auf Konjektur berahender Zusatz, } \\
& {\left[{ }^{\prime}\right.}=\text { zu beseitigender Einschub, } \\
& * * *=\text { Lücke, } \\
& ? \quad=\text { zweifelhafte Übersetzang. }
\end{aligned}
$$

